\title{
Representaciones sociales acerca de la delincuencia que tienen las menores de edad institucionalizadas en un centro de reeducación de la ciudad de Bogotá*
}

\section{Social representations about the crime that minors are institutionalized in a re-education center of the city of Bogotá}

\author{
Nancy Marina Vargas Espinosa* \\ Universidad Católica de Colombia, \\ Bogotá, Colombia \\ Centro Internacional de Educación y \\ Desarrollo Humano-CINDE, \\ Bogotá, Colombia \\ Universidad Pedagógica Nacional, \\ Bogotá, Colombia \\ Alfonso Sánchez Pilonieta** \\ Centro Internacional de Educación y \\ Desarrollo Humano-CINDE., \\ Bogotá, Colombia \\ Universidad Pedagógica Nacional, \\ Bogotá, Colombia
}

Recibido: 19 de noviembre de 2009

Revisado: 20 de diciembre de 2009

Aceptado: 2 de febrero de 2010

\section{Resumen}

La presente investigación tuvo como objetivo general conocer cuáles son las representaciones sociales que tienen las menores internas en una institución cerrada de reeducación en la ciudad de Bogotá, en la fase de ubicación. Como metodología se utilizó la técnica de discusión de grupo focal y a partir del análisis de discurso se plantearon las siguientes categorías: la conceptualización de la delincuencia, atribución de responsabilidad, legitimación de los actos delictivos y futuro. Los resultados analizados de acuerdo con dichas categorías muestran que las representaciones sociales sobre delincuencia reflejan que ésta se conceptualiza a partir de sus consecuencias, por su valoración, por su origen, por su instrumentación y por su conocimiento. La atribución de responsabilidad en la delincuencia se centra en sí misma, en relación con los demás, en la familia, en la sociedad y en la oportunidad que ésta brinda. La perspectiva de su futuro se ve influida en tres niveles: personal, institucional y social.

Palabras clave: representaciones sociales, delincuencia, niños institucionalizados.

Artículo de investigación.

Correspondencia: Nancy Marina Vargas Espinosa. Facultad de Psicología, Universidad Católica de Colombia. Centro Internacional de Educación y Desarrollo Humano-CINDE y Universidad Pedagógica Nacional. Correo electrónico: nmvargas@ucatolica.edu.co

... Alfonso Sánchez Pilonieta. Centro Internacional de Educación y Desarrollo Humano-CINDE. y Universidad Pedagógica Nacional. Correo electrónico: alsnchez@javeriana.edu.co 


\section{Abstract}

The general objective that this investigation had was to know the social representations that the underage boarders have in a closed institution of reeducation in Bogotá city, especially in the location stage. By the way, the methodology used was the discussion technique of the focal group and from the speech analysis it was set out the following categories of analysis: delinquency conceptualization, attribution of responsibility, legitimacy of criminal acts and future. The results that were analyzed according with those categories show that the social representations about delinquency are the result of its conceptualization from the consequences, assessment, origin, instrumentation and knowledge. The attribution of responsibility in delinquency focuses in itself in relationship with others in family, social life and the opportunities that society offers. The future prospect gets influenced in the levels: personal, institutional and social.

Key words: social representations, crime, institutionalized children

\section{Introducción}

La delincuencia es un fenómeno social que siempre ha estado presente en la historia de la humanidad, elemento que se modifica de acuerdo con el poder de grupos sociales, las circunstancias sociales y económicas del momento, las características de las personas que la construyen, la crean y la recrean y que le dan significado en el devenir de la comunicación en los diferentes grupos sociales.

Así, la criminología ha asumido por su carácter, estudiar la criminalidad. Molina (1994) define a la Criminología como "la ciencia que se ocupa del estudio de la génesis de la criminalidad, tanto como de la reacción social que tal fenómeno debía y podía suscitar" (p. 32); se ve aquí la importancia que cobra desde esta ciencia el determinar cuáles son las condiciones o factores que puedan explicar el fenómeno de la criminalidad, en relación con el delito.

Además, desde el punto de vista de Molina, puede entenderse por criminalidad aquello que "comprende no solamente la 'conducta delictiva', sino también la 'conducta desviada', de la que se desprende, en verdad, la primera fracción del objeto de estudio de la criminología la cual se ocupa del análisis de las 'conductas antisociales (1994, p. 33).

Las conductas antisociales pueden ser realizadas por cualquier sujeto que sea parte de un grupo social, y los adolecentes no se escapan a esto. Entonces al realizar la pregunta de quién es el adolescente que delinque y cómo se explica su comportamiento es necesario comprender inicialmente quién es ese joven y cuáles son los cambios más significativos que enfrenta. Esta etapa es considerada una de las más críticas del desarrollo del ser humano ya que entran en juego la rebeldía, lo novedoso, la fuerza física, la competencia, la buena presentación personal, la aventura y el desarrollo de actividades que están en contraposición con lo culturalmente establecido. Por tal motivo, algunas actividades fuera de la ley ofrecen en forma aparente la satisfacción de estas necesidades (Fundación FES, Fundación Restrepo Barco, 1998). La adolescencia marca un cambio en el pensamiento que se desarrolla tan discretamente que puede no percibirse. Esta nueva forma de pensar incluye una serie de habilidades separadas que empiezan a desarrollarse unos pocos años antes, pero que al principio sólo pueden utilizarse aisladamente.

También se puede mencionar otro cambio, el de la capacidad de reflexionar acerca de sus propios pensamientos, el de explicar el punto de vista de los otros. Según David Elkind (1985, citado por Hoffman, Paris \& Hall, 1996), los adolescentes que pueden deducir lo que piensan otras personas, tienden a centrarse más en sus deducciones que en lo que los otros piensan de ellos. Este nuevo tipo de egocentrismo es una característica de la primera etapa de la adolescencia. 
De otra parte, Rutter, Giller y Hagell (1988, citados por Vega, 1994) afirman que "en la adolescencia existe un aumento sustancial en la cantidad y espectro de las actividades delictivas como un cambio de patrón (absentismo escolar, vandalismo, robos), con un aumento de violencia al final de la adolescencia. Pero aunque la cantidad de actos delictivos aumenta, es probable que exista un aumento menor en el número de los individuos que cometen conductas antisociales. Al inicio de la edad adulta, aparece una disminución de la conducta antisocial, siendo muchos los delincuentes juveniles que dejan sus actividades, aunque no falten individuos que se inician en la delincuencia en estas edades" (p. 63). Garrido, Stangeland \& Redondo (1999) se refieren a que entre los 13 y los 18 años, las conductas delictivas aumentan y que surgen comportamientos tales como son la rebeldía propia de este periodo, pero que puede ir acompañada de violencia. Agregan que en edades posteriores, finaliza dichas actividades delictivas.

Según López Rey (1981), la delincuencia juvenil es concebida como algo distinto a la criminalidad, ya que tiene como protagonista a un niño o joven. Esto se afirmó conceptualmente en 1899, cuando se estableció el primer tribunal de menores en Chicago; lo que se buscaba con este tribunal era que éste se manifestase en favor no sólo del menor, sino también de la familia, para obtener mayores facilidades educacionales, mejores condiciones de trabajo y vida, y mayor libertad individual. Por tanto, el concepto de la delincuencia juvenil adquiere entonces un contenido propio, y su teoría como fenómeno explicativo aparece más adelante. Las teorías más frecuentemente mencionadas son etiquetamiento o reacción social, tensión, frustración, desadaptación, falta de madurez, subcultura, cambio social y desviación, entre otras. Unas tienen una condición médico psicológica; otras, sociológica; y algunas son combinación de ambos enfoques, puntualizando en el efecto irreversible de las causas, lo que explicaría la subsiguiente carrera criminal del menor al llegar a la edad adulta (López- Rey, 1981).

Dentro de las explicaciones de la delincuencia juvenil, vale la pena mencionar la propuesta de
Glueck y Glueck (1950), que enfatiza el desarrollo de controles internos debilitados como consecuencia de pobres prácticas de crianza y modelos paternos antisociales, como de predisposiciones temperamentales hacia la expresión de la energía agresiva y la búsqueda del interés personal. Una perspectiva más reciente sostiene que la conducta delictiva sirve de escape a una situación emocional temporalmente insoportable, que surge cuando las necesidades psíquicas del niño no son satisfechas, siendo estas necesidades básicas la autorrealización y la de recibir afecto, cuidado y protección de un adulto (Stoff, Breiling \& Maser, 2002). Otro marco de referencia en la explicación del fenómeno delictivo en jóvenes es el enfoque sociológico, en el que se sintetizan las principales teorías sociales tradicionales que intentan explicar el origen de la criminalidad con base en el análisis global de los factores sociales y sus diferentes interrelaciones, que pueden afectar la vida diaria de las personas y producir una conducta antisocial (Garrido \& Vidal, 1989).

Por su parte, la teoría de la subcultura sugiere que la delincuencia juvenil aparece como una conducta normal dentro de una subcultura particular, que puede ser aprendida como cualquier otra forma de cultura social (López Rey, 1981).

La teoría diferencial de Cloward y Ohlin, conocida como de la baja delincuencia, también intenta dar explicación al fenómeno de la delincuencia juvenil. Según ella, los niños con una mala educación, que sufren privaciones económicas o tienen una cultura pobre se unen con las juventudes de otros barrios que se encuentran en análogas circunstancias y que unidos en bandas encuentran suficiente fuerza para rechazar el sistema de valores de la sociedad, reemplazándola con una de su propia cosecha e intentando llevar por medios ilegales lo que no pueden obtener legítimamente (Garrido \& Vidal, 1989).

Por otro lado, de acuerdo con Gibbons (1980), los jóvenes delincuentes surgen de aquellas fusiones en las que hay una integración previa de patrones sociológicos delictivos y otros admisibles convencionalmente, y donde la organización social es estable y los jóvenes pueden tener un aprendizaje en la carrera del crimen (Garrido et al., 1999). 
Generalmente, los estudios de la delincuencia juvenil se han centrado en población masculina. En cuanto a la delincuencia juvenil femenina, se puede señalar que los estudios sobre ella se iniciaron hacia finales de los años sesenta, momento que se relaciona con el movimiento de liberación femenina. Sobre esta problemática se encuentran algunas teorías explicativas, tales como las teorías clásicas (biológicas, psicoanalíticas y psiquiátricas); teorías intermedias de índole individualista con proyección social, como Thomas Pollack y Cowie; y teorías de carácter social de enfoque funcionalista (teorías del rol y teoría de la igualdad de oportunidades) y de enfoque crítico (teorías del control social y teoría de la dependencia económica).

Es innegable que "en todos los países del mundo hay más hombres delincuentes que mujeres" (Garrido et al, 1999, p. 304), cuestión que ha llevado a indagar por tales diferencias.

Con respecto a las teorías clásicas, éstas pretendieron explicar la delincuencia femenina fundamentada en aspectos individuales, ya fuera de contenido biológico (anormalidades bioantropológicas, desarrollo sexual, etc.) o de contenido psicoanalítico o psiquiátrico, en los que se comparaba la delincuencia femenina con trastornos biológicos o psíquicos.

Sin embargo, la evolución criminológica se ha orientado más hacia una perspectiva social (superando de esa manera el determinismo biológico-individual), que ha fundamentado otras teorías explicativas de la delincuencia femenina, como son la ecología criminal, el aprendizaje social y la teoría del etiquetado. Pero sin duda los principales aportes a la explicación de dicho fenómeno provienen de las teorías funcionalistas y de la criminología crítica.

Por mencionar algunos de estos estudios se pueden referenciar los realizados desde una perspectiva epidemiológica, los que permiten concluir que estas diferencias son dadas por los factores socioculturales, resultado de la socialización diferenciada para hombres y para mujeres. Giddens (1993) plantea al respecto que "muchas mujeres están socializadas para valorar diferentes cualidades de la vida social que los hombres" (Garrido et al., 1999, p. 308). Los estudios criminológicos sobre la delincuencia juvenil señalan el carácter multicausal del fenómeno, pero a pesar de ello se pueden señalar algunos factores que parecen decisivos en el aumento de la delincuencia juvenil. Son factores que se encuentran en la base de la delincuencia juvenil, la imposibilidad que tienen muchos grupos de la juventud de integrarse al sistema y en los valores que éste promociona como únicos y verdaderos (en el orden material y social, por ejemplo), y la propia subcultura que genera la delincuencia que se transmite de pandilla en pandilla, de modo que cada nuevo adepto trata de emular y, si es posible, superar las acciones violentas realizadas por los miembros anteriores del grupo (Garrido, 1984).

Clemente y Espinosa (2001) plantean otros factores que hacen referencia a riesgos y protección:

a) Factores del niño como el temperamento, el rendimiento académico, los niveles de incontrolabilidad de la conducta, la elevada emocionalidad e inadaptabilidad social, la impulsividad, el autocontrol y la búsqueda de sensaciones. Todos ellos correlacionan positivamente con la delincuencia juvenil.

b) Influencias familiares, hogares conflictivos y multiproblemáticos son característicos de prácticas de disciplina irregular e inconsistente, en las que la calidad de las relaciones está marcada por menor afecto, apoyo emocional y apego. La comunicación se torna defensiva y las actividades familiares compartidas son escasas o inexistentes; el hijo es espectador y en ocasiones víctima de la agresividad familiar, de forma que acaba desarrollando una personalidad patológica.

c) Factores escolares, pues la escuela continúa la labor socializadora iniciada por la familia, facilita el acceso a la cultura y al desarrollo social entre iguales. Si la relación en este entorno resulta frustrante, el desarrollo de las capacidades y la integración social se ven seriamente afectados. 
Los factores de protección y su forma de influencia son menos conocidos que los factores de riesgo, no obstante, se piensa que al igual que estos últimos, no actúan individual, directa y unidireccionalmente, sino dentro de un entramando de circunstancias y de interacciones que determinan en última instancia la no presencia de la conducta antisocial.

Para Farrington (1995, citado por Torrente \& Merlos, 1999), entre los ocho y los diez años los más importantes predictores de la delincuencia son: la conducta antisocial, es decir, conducta deshonesta, problemas escolares y agresión; a esto se suma hiperactividad, impulsividad, déficit atencional, baja inteligencia; pobre logro escolar, criminalidad familiar, pobreza familiar y, por último, pobres prácticas educativas.

A manera de conclusión se puede decir que el grupo de adolescentes es un grupo poblacional vulnerable y frágil debido no sólo a elementos de contexto, como el ambiente familiar, social, de amigos y de factores igualmente trasmitidos por la familia como son todos los elementos hereditarios, sino también a todos los cambios psicológicos propios de la edad y de la etapa.

Son varios los factores que se conjugan para que un joven llegue a delinquir. Su pensamiento de autosuficiencia en un ambiente que es propicio, por los elementos antes mencionados, hace que el fenómeno de delincuencia sea multicausal, es decir, no se le puede atribuir a un solo elemento de origen; de alguna manera la multiplicidad epistemológica que pretende explicar la delincuencia en general y la delincuencia juvenil en particular lo demuestra, planteamientos que involucran enfoques biológicos o psicológicos o sociales, y que por sí solos se quedan cortos para explicar el fenómeno.

Hablar de delincuencia supone, entonces, conceptos, significados y valoraciones que no están lejos de la manera en que se ve la vida. Analizar los grupos implicados en esta desviación implica entrar a un mundo complejo con similitudes y diferencias dependiendo de los tipos de sociedad, su momento histórico, cultura y grupo social.
Las representaciones sociales permiten acercarse al conocimiento de los componentes valorativos que orientan la postura del sujeto frente al objeto representado y que determinan su conducta hacia él. De acuerdo con Ibáñez (1988), la representación social cumple una función importante en la generación de tomas de postura frente a la realidad. Como dice Moscovici (1974) la teoría de las representaciones sociales es en esencia el estudio del conocimiento social, en el que entra todo lo que forja a una sociedad (costumbres, creencias compartidas, prácticas sociales).

La teoría de las representaciones sociales tiene sus raíces en la Psicología social francesa, a partir del trabajo elaborado por Moscovici, quien tenía como vértice el recuperar los procesos meramente sociales de la Psicología social, enfocándose en los procesos compartidos y colectivos. A partir de la postura inicial de este autor se han desarrollado otras líneas. A este respecto, Pereira de Sá, 1998, citado por Banch, 2000 comenta que son tres las líneas de desarrollo teórico en las representaciones sociales: una que es desarrollada por Dense Jodelet, que parte de la complejidad de las representaciones sociales, desarrollo cercano a la propuesta inicial de Moscovici; la otra está centrada en los procesos cognitivos, la propuesta en Aix en Provence por Jean Clude Abric, ampliada alrededor de la estructura de las representaciones sociales y que da pie a la teoría del núcleo central; y la tercera, con un enfoque más sociológico es la desarrollada en Ginebra por Willem Dosie, quien se centra en las condiciones de producción y circulación de las representaciones sociales.

Desde los planteamientos iniciales de Moscovici hasta los de autores más recientes se encuentra que las representaciones sociales conservan fundamentalmente dos componentes: los mecanismos cognitivos y el interaccionismo social. Éstos permiten la construcción de las representaciones a partir de condiciones de producción tales como:

Los medios de comunicación social, interacción cara a cara, comunicación y lenguaje; también como las condiciones de circulación de las representaciones sociales (intercambio 
de saberes y ubicación de las personas en los grupos naturales y de los grupos sociales naturales en contextos sociales especiales dentro de la estructura social y funciones sociales, construcción social de la realidad en el intercambio social, desarrollo de una identidad personal y social, búsqueda de sentido y construcción de conocimientos del sentido común (Banch 2000 cita a Pereira de Sá, 1998, p. 3).

El lenguaje juega un papel importante en la transmisión y comunicación de símbolos y significados y es a través de él que se construyen las relaciones sociales que llevan a la internalización de las normas y valores que, a su vez, le permiten su construcción como individuos. Esa interacción aprueba la construcción y reproducción de las relaciones sociales y que por medio del lenguaje se construyen las representaciones sociales.

Por representaciones sociales se entiende el conjunto de fenómenos de carácter cognitivo que hacen las personas dentro de un contexto específico en torno a la realidad. Es decir, es el ejercicio que las personas hacen para tener una lectura de la realidad en la cual se desenvuelven, lo que lleva a tomar posiciones en relación con ésta (Gutiérrez, 1998). Moscovici señala que:

Representación social es una modalidad particular de conocimiento, cuya función es la elaboración de los comportamientos y la comunicación entre los individuos. La representación social es un corpus organizado de conocimientos y una de las actividades psíquicas gracias a la cual los hombres hacen inteligible la realidad física y social, se integran en un grupo o en una relación cotidiana de intercambios, liberan los poderes de su imaginación (Moscovici, 1979, citado por Mora, 2002, p. 7).

\section{Moscovici dice que}

la representación social es una modalidad particular de conocimiento, cuya función es la elaboración de los comportamientos y la comunicación entre los individuos. La representación social es un corpus organizado de conocimientos y una de las actividades psí- quicas gracias a la cual los hombres hacen inteligible la realidad física y social, se integran en un grupo o en una relación cotidiana de intercambios, liberan los poderes de su imaginación (Moscovici, 1979, citado por Mora, 2002, p. 7).

Según Alzate, Arbeláez \& Arango (2002), la representación social es una forma de interpretar y pensar la realidad cotidiana y es una forma de conocimiento social. Es, a su vez, la actividad mental, actividad por grupos y por sus individuos con el propósito de fijar posiciones con respecto a situaciones, acontecimientos y comunicación que le competen. Lo social participa a través del contexto en que se mueven los individuos, de la comunicación que se da entre ellos y a través de los marcos de aprehensión que produce el bagaje cultural, de los códigos, valores e ideologías relacionados con las posiciones y pertenencias sociales.

El propio Moscovici hacía énfasis sobre la dimensión irreducible de las representaciones sociales, afirmando que éstas corresponden a una forma de organización psicológica y social que no se puede equiparar a ninguna forma de conocimiento (Moscovici, 1976, citado por Ibáñez, 2001). De esta forma, Moscovici resaltaba la diferencia tan notoria que existe entre las representaciones sociales y las otras formas de conocimiento social, entre las cuales se encuentra los mitos y la ideología, entre otras cosas.

Ahora bien, en la formación de las representaciones sociales se dice que existen varios factores que inciden en este proceso, que se conoce como fuentes de determinación. Estas fuentes de determinación caracterizan a una sociedad y la distinguen de otra en cuanto al sistema de creencias y valores que circulan en ella. Hay tres fuentes de determinación: la primera de ellas hace referencia a los factores sociales, los económicos y a los históricos. La segunda hace referencia al proceso dinámico de las representaciones sociales y de sus estrategias de formación, en las que se destacan dos procesos importantes: la objetivación y el anclaje. 
La objetivación consiste en la forma en que los saberes y las ideas sobre determinados objetos entran a ser parte de las representaciones sociales de estos objetos por medio de una serie de cambios particulares. Y el anclaje hace referencia al modo como inciden los esquemas ya elaborados en la generación de otras representaciones sociales.

Por último, la tercera fuente de determinación consiste en las prácticas sociales, específicamente aquellas relacionadas con las diferentes formas de comunicación social, porque es allí básicamente donde se generan las representaciones sociales, destacando la importancia que desempeñan las conversaciones en la producción y mantenimiento de éstas (Ibáñez, 2001).

Con respecto a la objetivación y el anclaje, Jodelet (1993, citado por Cortés, 2002) dice que estos dos procesos se refieren a la elaboración y funcionamiento de una representación social y estos muestran la interdependencia entre la actividad psicológica y sus condiciones sociales; en cuanto a la objetivación dice que es lo social en la representación:

En este proceso la intervención de lo social se traduce en el agenciamiento y la forma de los conocimientos relativos al objeto de una representación articulándose con una característica del pensamiento social, la propiedad de hacer concreto lo abstracto, de materializar la palabra. De esta manera la objetivación puede definirse como una operación formadora de imagen y estructurante (p. 10).

En lo que respecta al anclaje, este se considera la representación en lo social. Este proceso refiere al enraizamaiento social de la representación y de su objeto. La intervención de lo social se trasforma en el significado y la utilidad que le son otorgados al objeto. El anclaje compromete otro componente cognitivo del objeto representado dentro de un sistema de pensamiento que ya existe y a los cambios que resultan de este sistema. "Ya no se trata como en caso de la objetivación, de la constitución formal de un conocimiento, sino de su inserción orgánica dentro de un pen- samiento constituido" (Cortés, 2002, p. 10). En la relación dialéctica con la objetivación, el anclaje cumple tres funciones: integración de novedades, interpretación de la realidad y orientación de las conductas y las relaciones sociales. Lo que hace que se diferencie de la objetivación es que ésta, según Moscovici: "permite incorporar lo extraño en lo que crea problemas, en una red de categorías y significados" $(1984$, p. 11)

Con base en lo anterior, este trabajo se propuso conocer cuáles son las representaciones sociales acerca de la delincuencia que tienen las menores institucionalizadas y que están en la fase de ubicación en una institución cerrada. Es útil conocer las distintas imágenes acerca de la delincuencia, que descansan en representaciones sociales de grupo que cuentan con realidades y culturas diversas a las que se pretende abordar, analizar o beneficiar.

\section{Método}

El acceso a las representaciones sociales es posible desde el enfoque cualitativo, que incluye la descripción y el análisis del discurso de los sujetos; la técnica de investigación fue la de grupo focal, cuyo foco era el significado de la delincuencia.

\section{Participantes}

En total, el número de participantes corresponde a la población de menores que estaban en fase de ubicación, distribuidas en tres hogares, que poseían las mismas características. Las edades de las menores oscilaban entre 12 y 18 años, con niveles educativos, en su mayoría, de primaria, algunas analfabetas y dos solamente con nivel de bachillerato, provenientes de estratos bajos, de hogares rotos y familias disfuncionales, cinco son madres, con dos y tres niños; en su mayoría se dedican a actividades como vendedoras ambulantes y habitantes de la calle. Un número bajo han reincidido en actividades delictivas. Los delitos por los que están allí son principalmente contra el patrimonio, le siguen delitos relacionados con la venta y consumo de sustancias psicoactivas $y$, en tercer lugar, delitos violentos como lesiones personales y homicidios. 


\section{Procedimiento}

Para el desarrollo de la investigación se determinó la temática a trabajar y se inició el trabajo de recolección de información pertinente. Se seleccionaron las menores de acuerdo con el cumplimiento del requisito de estar en fase de ubicación dentro de la institución, se organizaron los grupos y se hizo con cada uno de ellos la entrevista con base en la guía realizada previamente, es decir, las preguntas relacionadas con las primeras categorías, teniendo cuidado de iniciar con preguntas más generales hasta ir focalizando las temáticas que se querían indagar respecto a la representación social de la delincuencia.

Cada sesión de discusión tuvo aproximadamente una hora de duración. Se realizaron las transcripciones y se establecieron las categorías definitivas de análisis, las que emergieron después de identificar los elementos que eran comunes y que se pudieron agrupar en conjuntos, teniendo cuidado de que los elementos de uno no pertenecieran a otro, y se definieron conceptos que se adecuaran a esas categorías. Posteriormente, se hicieron las interpretaciones propias de la información y se elaboraron la discusión y las conclusiones.

\section{Definición metodológica de las representaciones sociales}

Representación social de la delincuencia se refiere a la posición valorativa que las menores tienen acerca de la delincuencia, es decir, una manifestación simbólica de algo real, que es parte de su cotidianidad y que forma parte de su conocimiento social. Para el análisis de las representaciones sociales de las jóvenes que participaron en este estudio se tomaron en cuenta las siguientes categorías:

Actitud: disposición ya sea de carácter positivo o negativo que tiene la persona cognoscente sobre el objeto cognoscible, es la posición evaluativa del objeto. Dinamiza las conductas hacia el objeto representado.
Información: conocimientos que tienen sobre el objeto social (desde adentro como participante en la creación de la representación, cuando se tiene contacto con el objeto, diferente cuando es brindada por la comunicación).

Campo de representación: corresponde al orden y la jerarquización que se hace de la representación social (Núcleo figurativo); este campo se construye por la objetivación que resulta de pasar (transformar) los diferentes contenidos conceptuales a iconos. Se relaciona con construcción selectiva la que consiste en que los grupos se apoderan de la información y del conocimiento sobre un objeto determinado.

Esquematización estructurante: proceso de organización que se desarrolla por la apropiación, para proporcionar una imagen dándole un significado global.

Naturalización: aspectos valorativos.

Anclaje: se refiere al cómo influyen los esquemas ya elaborados en la generación de las representaciones, a sus inserciones de las representaciones en el universo de saberes preexistentes como instrumentación de ese saber, es decir, el valor funcional que se le atribuye conforme la dinámica de las relaciones.

\section{Resultados}

Las categorías que quedaron en definitiva y que permitieron el análisis de la información fueron:

Conceptualización sobre la delincuencia: incluye dimensiones relacionadas con las consecuencias de la delincuencia en niveles físicos o emocionales, por su valoración (positiva o negativa, buena o mala), por su origen, por su instrumentación y por su conocimiento.

Atribución de responsabilidad: incluye lo que se dice acerca de las razones por las que se delinque. Entre estas están las que se relacionan con el sujeto mismo, con los otros, con la familia, en 
la que se desarrollan estilos de autoridad, afecto y comunicación que consideran y determinan su actuar delictivo; en cuanto a la sociedad razonan acerca de que el rotulado que ésta hace, influye en su responsabilidad.

Legitimación de sus actos delictivos: incluye reflexiones sobre las apreciaciones acerca de situaciones, eventos y circunstancias en que se justifica el delinquir, que pueden ir desde la respuesta sin control subjetiva ante una situación, o por experiencia previa (por ejemplo, maltrato recibido), hasta la respuesta adecuada para sobrevivir sin importar a quién se le pueda hacer daño; en algunos casos se considera que dicha respuesta corresponde a una aprobación divina (Dios), pues dicha divinidad conoce porqué se hace.

Futuro: esta categoría incluye la reflexión acerca de qué será la vida futura fuera de la institución y qué variables de orden personal como temores, motivaciones, incertidumbres, sentimientos y cambios pueden afectarlo, o cómo puede también encontrar o perder el apoyo en oportunidades institucionales y sociales.

Los resultados mostraron que las menores recluidas en el hogar femenino, en la fase de ubicación, poseen significados similares acerca de lo que es la delincuencia, los que permitieron realizar un análisis de las estructuras básicas de la representación social y, por tanto, cumplir con los objetivos del presente trabajo.

De manera general y compartida por las menores de los tres hogares abordados, la delincuencia es percibida como una situación de la cual ellas han sido víctimas. Aunque la ven como una forma de vida, una opción o un medio de subsistencia que trae algo "malo" para ellas (consecuencias negativas) y para otras personas como son los miembros de su familia; sin embargo, lo continúan hacien- do. La atribución de su condición (unas aceptan su condición de delincuentes, otras no) la basan principalmente en variables externas a ellas, apreciaciones que incluyen que la sociedad las rotula o les niega las oportunidades, que la familia es uno de los principales responsables, que es consecuencia de la falta de apoyo y de afecto. o de rechazo y rabia, o por otras circunstancias que las "obligaron" a hacerlo, como son las variables de orden económico, especialmente la pobreza.

Sus conductas delictivas son legitimadas por expresiones relacionadas con la aceptación de la delincuencia como una opción de trabajo, o una respuesta a la experiencia propia del maltrato recibido, o como una forma de evitar algo peor "es mejor robar que prostituirse" o es algo que de alguna manera Dios permite y apoya. Se acepta la delincuencia como medio para tomar lo que se necesita "solo robar para vivir". Sin embargo, se encontraron apreciaciones relacionadas con una negativa a aceptar tal legitimación, pues consideran que no es justo quitarle a otra persona algo que haya conseguido con esfuerzo, además que no comprenden por qué se tiene que hacer.

En cuanto a la categoría de análisis acerca del futuro, en general se quiere dejar esa vida, dejar de delinquir. Unas menores centran más sus posibilidades en ellas mismas, otras en el apoyo dado por la institución actual y otras en las alternativas dadas por la sociedad como son oportunidades laborales y apoyo de otras instituciones diferentes a las de reeducación (iglesias, Bienestar Familiar, entre otras).

En las tablas 1, 2, 3 y 4, se presentan los elementos estructurales de las representaciones sociales en cada una de las categorías, tomadas en cuenta para el análisis de los resultados. En la columna de la derecha se encuentran las representaciones manifestadas verbalmente en los grupos focales. 
Tabla 1. Categoría conceptualización de la delincuencia

\begin{tabular}{|c|c|c|}
\hline CATEGORÍA & $\begin{array}{l}\text { ESTRUCTURA DE LA } \\
\text { REPRESENTACIÓN } \\
\text { SOCIAL }\end{array}$ & TEXTO \\
\hline \multirow{18}{*}{$\begin{array}{l}\text { CONCEPTUALIZACIÓN } \\
\text { DE LA DELINCUENCIA }\end{array}$} & & Dimensión: Por sus consecuencias \\
\hline & Objetivación & Es causar daño, es como cierto grado de mal, de daño. \\
\hline & Anclaje & $\begin{array}{l}\text { También nos convertimos en un daño para nosotras y para los demás } \\
\text { porque, como también cometemos errores. }\end{array}$ \\
\hline & Información & $\begin{array}{l}\text { Hay que pensar en el daño que se le puede llegar a hacer en las de- } \\
\text { más personas. Y la pregunta, por qué se benefician de la violencia, } \\
\text { por qué unas personas piensan para actuar y otras no lo hacen, pero } \\
\text { eso son los demás; a mí personalmente me ha proporcionado dolor en } \\
\text { el momento de cometer el acto. }\end{array}$ \\
\hline & & Dimensión: Por su valoración \\
\hline & Naturalización & Pero la vida de un ladrón es una cárcel o el cementerio. \\
\hline & Anclaje & $\begin{array}{l}\text { Muchas veces piensa que ¡bueno robar ya me solucionó el problema! } \\
\text { Pero no, detrás de eso puede traer muchas consecuencias, como es- } \\
\text { tar encerrado, como que lo maten, trae muchas consecuencias. }\end{array}$ \\
\hline & Información & Romper con las normas que ya se han establecido. \\
\hline & & Dimensión: Por su origen \\
\hline & $\begin{array}{l}\text { Esquematización } \\
\text { estructurante }\end{array}$ & $\begin{array}{l}\text { La delincuencia no es sólo lo que uno hace, delincuencia es lo que la } \\
\text { comunidad quiere llamar, allá están los delincuentes, o porque están } \\
\text { abajo o porque están en una esquina fumándose un cigarrillo, enton- } \\
\text { ces son delincuentes, eh también hacen parte de delincuencia lo que } \\
\text { la sociedad llama a los jóvenes del barrio, delincuentes. }\end{array}$ \\
\hline & Objetivación & $\begin{array}{l}\text { Porque muchas veces uno se la pasa con las amistades del barrio } \\
\text { tarde en la noche en la calle, o en la esquina de la casa, en el andén } \\
\text { de al frente fumándose un cigarrillo o otra clase de sustancias, si ve } \\
\text { porque uno ha recorrido y uno es sincero, de verdad uno "paqué" se } \\
\text { va poner ahí... si uno anda entre parchecitos así, pues se supone que } \\
\text { uno va conociendo de todo un poquito, de todo se ve en esta vida, } \\
\text { de lo bueno y de lo malo. Entonces es eso que la sociedad lo quiere } \\
\text { llamar delincuentes. }\end{array}$ \\
\hline & & Dimensión: Por su instrumentalización \\
\hline & Objetivación & $\begin{array}{l}\text { Para conseguir el dinero rápido y fácil, la plata fácil, es la manera en } \\
\text { la cual nosotras vemos el acomodo de tener las cosas sin lucharlas. }\end{array}$ \\
\hline & Anclaje & $\begin{array}{l}\text { Yo opino lo mismo, pues si uno incurre a veces, a uno no le gusta tra- } \\
\text { bajar, no le gusta las cosas así, es lo más rápido, lo más fácil. }\end{array}$ \\
\hline & Objetivación & $\begin{array}{l}\text { Algo también es porque habemos muchas personas que nos acostum- } \\
\text { bramos a hacerlo, a ser delincuentes, a ser nombrados y juzgados } \\
\text { como eso, como delincuentes y para hacerlo entonces ya busca la } \\
\text { manera y tiene sus horarios establecidos para ir a hurtar. }\end{array}$ \\
\hline & & Dimensión: Por su conocimiento \\
\hline & Información & $\begin{array}{l}\text { La delincuencia es cuando uno comete un delito o algo, cuando uno } \\
\text { roba. }\end{array}$ \\
\hline & Información & $\begin{array}{l}\text { La delincuencia no es solamente robar, sino que eso va incluido con } \\
\text { robar, secuestro, todo eso, eh... homicidio, todo eso va, va en un } \\
\text { solo círculo que pues, en ocasiones uno piensa que por qué uno está } \\
\text { haciendo las cosas. }\end{array}$ \\
\hline
\end{tabular}


Tabla 2. Categoría atribución de la responsabilidad

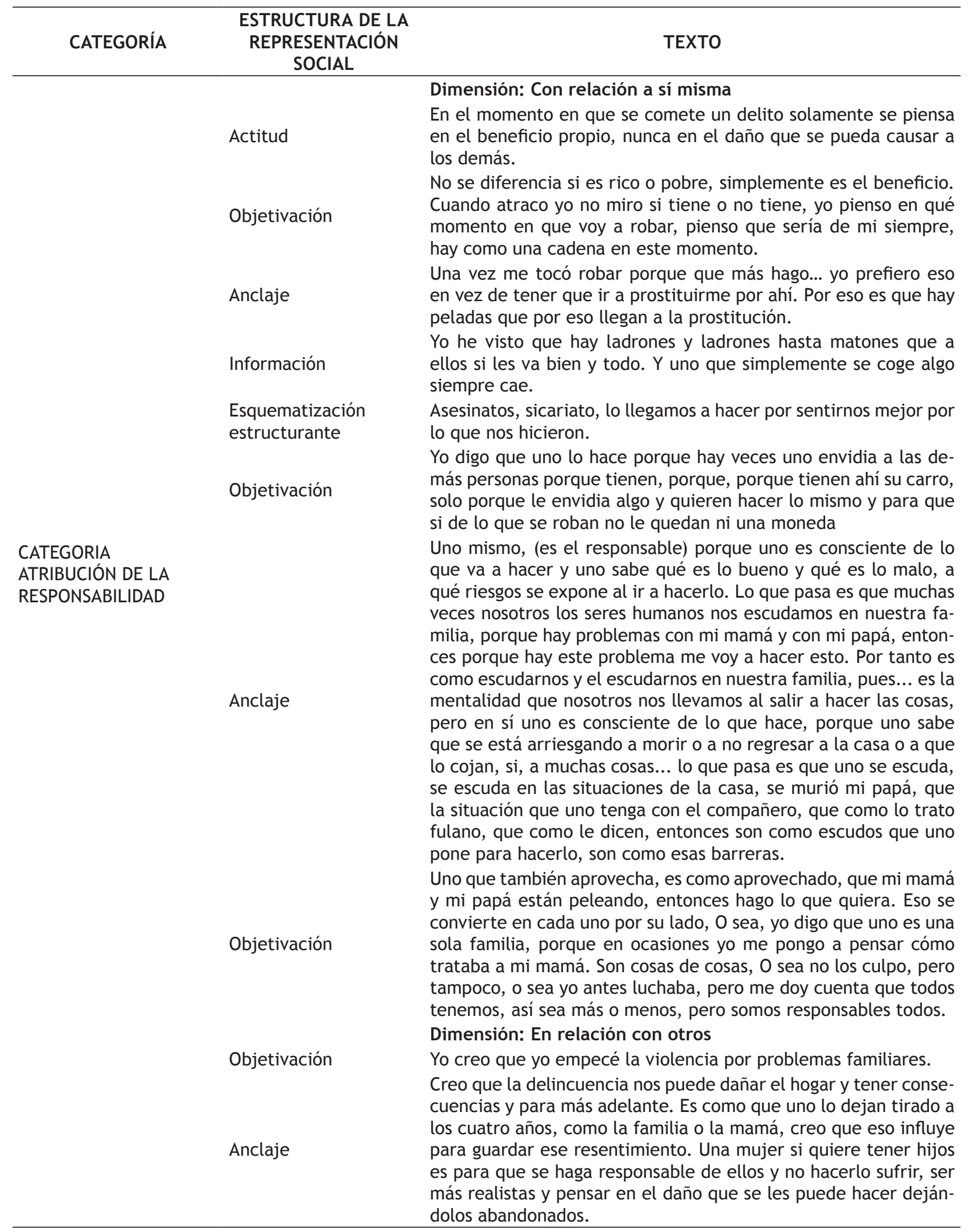


ESTRUCTURA DE LA REPRESENTACIÓN SOCIAL

Información

Información

Objetivación

Anclaje

Núcleo Figurativo

Objetivación

Naturalización

Anclaje

Objetivación
TEXTO

Por influencia de una compañera, de tener las cosas de moda o lo más necesario.

Pero es que casos se han visto, porque es que, si uno antes de conseguirse un compañero y sabe que ese compañero es trabajador que es estudiado y todo eso, uno sabe con que se metió, pero si uno se mete con un ladrón, pues toda la vida va a vivir con un ladrón y pues va a robar, porque así los distinguí pues le toca aguantárselo como es. ¿Si me hago entender?, entonces, es como el tipo de vida que uno mismo quiere para uno, porque si uno es consciente que se va a meter con una persona que lo va a ayudar lo va a guiar por buenos caminos, que va a salir adelante y que va a luchar por una familia, pues es una persona de bien y no va a tener necesidad de hacerle daño a nadie. Pero si uno sabe que se va a meter con un ladrón marihuanero, a fumar marihuana toda la vida y a robar, y los hijos pues nacen igual, uno cría, cría lo que es. Pues yo pienso así no. Es eso. Es como eso, que las personas reconocemos lo que seremos, ¿o no?

Dimensión: En la familia, factor autoridad

Por lo menos en mi caso, ya desde los 11 años me tocó asumir cosas que, todavía no era, por los menos desde pequeña hasta los once mi vida era normal, porque vivía con mi papá, 0 sea, todo marchaba bien, ya después de ahí para allá todo se derrumbo, me sentía sola, como que no encuentro como llenar esos vacíos. También en ocasiones es como, como, se me olvidó, jaaah! Es como que también le dan responsabilidades a uno, que no, que no son de uno, que a veces, porque usted cumple el rol de hermana mayor usted tiene que hacerse cargo de sus hermanos, eh, yo a tal hora, se tiene que quedar a cocinar a hacer lo que no le corresponde a uno, y tal vez por eso nosotras dejamos los estudios atrás, como que eso ya no nos interesa y por preocuparnos más, no están exigiendo otro tipo de cosas.

Dimensión: En la familia, factor afecto

Yo digo que la delincuencia no sólo va entre nosotras mismas, sino también va con familiares, con los tíos, con los primos, con los hermanos porque ellos son los que los ponen a uno a vender, que meta, que trabaje, que traiga, que vaya y robe que tranquilo que si usted cae yo voy y la saco.

O también que la mamá está mal y como que jay! Mi mami está mal, entonces la mamá ya ve que la hija lo hace, entonces vuelve y se hace la que está enferma.

Y buscarnos que los adultos nos protejan y no nos obliguen a hacer cosas o delito.

También es como el abandono, cuando ellos salen y se van, como con hartas responsabilidades, lo hacen ver como si ya fuera malo, usted tiene que trabajar, usted tiene que hacer usted tiene..., 0 sea ya es su vida, ya o sea lo surtean a uno.

Dimensión: En la familia, factor comunicación

Pues responsable, mi papá, mi mamá, responsables nosotros tres, pues tengo la mayor parte de la responsabilidad, pues porque en mi casa nunca hubo comunicación, nunca hubo comprensión, siempre como cuando uno hace algo mal como que, si hice mal yo le pego y esa es la manera que ella tiene que aprender. 


\begin{tabular}{|c|c|c|}
\hline \multirow[t]{5}{*}{ CATEGORÍA } & $\begin{array}{l}\text { ESTRUCTURA DE LA } \\
\text { REPRESENTACIÓN } \\
\text { SOCIAL } \\
\end{array}$ & TEXTO \\
\hline & & Dimensión: En la sociedad, factor rotulado \\
\hline & Anclaje & $\begin{array}{l}\text { Tal vez por el rechazo de la sociedad, que porque ella sí, ella no, } \\
\text { como que nos ven como personas diferentes a cada uno, enton- } \\
\text { ces la familia también. }\end{array}$ \\
\hline & Núcleo figurativo & $\begin{array}{l}\text { La gente de pronto piensa que uno va a pedir todos los días... to- } \\
\text { dos los días se lo pasa pidiendo... y la gente dice no si la he visto } \\
\text { que pasa todos los días por aquí y se lo pasa pidiendo, pasa por } \\
\text { tales horas, entonces es eso. Por algunos pagan todos, ya llegan } \\
\text { otros que de verdad necesitan y le dicen no, no, no... Como que } \\
\text { le cierran las puertas, por unos pagan todos. }\end{array}$ \\
\hline & Objetivación & $\begin{array}{l}\text { A veces dicen ay colabóreme con una monedita y puch! le pegan } \\
\text { el raponazo (risas). La gente ya tiene desconfianza porque cuan- } \\
\text { do ya se le va a acercar se le va corriendo, porque ya le pasó la } \\
\text { primera vez. }\end{array}$ \\
\hline
\end{tabular}

Tabla 3. Categoría legitimación de los actos delictivos

\begin{tabular}{|c|c|c|}
\hline CATEGORÍA & $\begin{array}{l}\text { ESTRUCTURA DE LA } \\
\text { REPRESENTACIÓN } \\
\text { SOCIAL }\end{array}$ & TEXTO \\
\hline \multirow{6}{*}{$\begin{array}{l}\text { LEGITIMACIÓN DE LOS } \\
\text { ACTOS DELICTIVOS }\end{array}$} & $\begin{array}{l}\text { Esquematización } \\
\text { estructurante }\end{array}$ & $\begin{array}{l}\text { ¡Ah! Pues en parte sí... a mi sí, o sea por ejemplo yo robo, si veo } \\
\text { que mis hijos están aguantando mucha hambre y voy a una tien- } \\
\text { da y pido y no me da entonces... yo justifico... }\end{array}$ \\
\hline & Objetivación & $\begin{array}{l}\text { Pero hay casos de casos, en mi caso mi padrastro no fue lo que } \\
\text { más esperaba, me acosaba y era muy violento conmigo por eso } \\
\text { uno llega a justificarse para hacer las cosas. }\end{array}$ \\
\hline & Núcleo figurativo & $\begin{array}{l}\text { Pero yo también creo, pues no sé, yo tengo mucha fe en Dios y yo } \\
\text { sé que si uno va con Dios, así lo vean quieto, nada, yo no tengo } \\
\text { nada que temer y puede que en ese momento hayan personas } \\
\text { que lo auxilien a uno y se alejan. Son cosas que mi Dios le pone } \\
\text { a uno. }\end{array}$ \\
\hline & Objetivación & $\begin{array}{l}\text { Digamos uno se echa la bendición y no pues yo voy con Dios, y } \\
\text { pues sí, porque mi Diosito sabe en qué situaciones vive uno, uno } \\
\text { pues uno se robó algo, y pues si uno lo ganó, gracias Diosito, } \\
\text { gracias a Él, Diosito lo escuchó, porque Él sabe que no es para } \\
\text { nada malo. }\end{array}$ \\
\hline & Anclaje & $\begin{array}{l}\text { Uno también se encomienda a Él porque uno se expone a muchos } \\
\text { peligros también, porque no falta el que diga a uno quién fue, } \\
\text { y le salga a uno con una pistola y nosotras con una navaja, iqué } \\
\text { vamos a hacer pues más peligrosas para nosotras! O a veces que } \\
\text { uno lleva del bulto porque le dan pata, bueno mejor dicho, nos } \\
\text { mechonean, nos pegan... }\end{array}$ \\
\hline & Naturalización & $\begin{array}{l}\text { No, no, no, no, no, o de pronto en partes si, tiene que ser ya } \\
\text { algo, ya fuera de lo normal para uno tener que hacerlo, pero } \\
\text { en sí yo no veo porque nosotros los seres humanos acudimos a } \\
\text { estar hurtando... habiendo tantas formas de poder conseguir la } \\
\text { plata y pues hay un dicho que dice ayúdate que yo te ayudaré, y } \\
\text { yo creo que poco a poco uno la va levantando sin necesidad de } \\
\text { hacerle daño a nadie. }\end{array}$ \\
\hline
\end{tabular}


Tabla 4. Categoría futuro

\begin{tabular}{|c|c|c|}
\hline CATEGORÍA & $\begin{array}{l}\text { ESTRUCTURA DE LA } \\
\text { REPRESENTACIÓN } \\
\text { SOCIAL }\end{array}$ & TEXTO \\
\hline \multirow{9}{*}{ FUTURO } & & Dimensión personal: Temores \\
\hline & Anclaje & $\begin{array}{l}\text { Para volver a caer es de que uno se haya criado en un ambiente de } \\
\text { maltrato y como no hay la elección de elegir o de opinar sino estar } \\
\text { sujeto a los padres y a sus órdenes. }\end{array}$ \\
\hline & Naturalización & $\begin{array}{l}\text { O si no también de que, de que, acá si nos dan gabela y decimos } \\
\text { que nunca volvemos a una cárcel, y como que pensamos para lo } \\
\text { contrario... entonces no cambia.... en estos momentos que es- } \\
\text { tamos acá y cuando menos piense estamos por allá en el Buen } \\
\text { Pastor.... no cambiamos, sale uno como más ¡uich! }\end{array}$ \\
\hline & Objetivación & $\begin{array}{l}\text { Bueno, pero para eso pues yo pregunto y digo no, si uno a veces, } \\
\text { por ejemplo yo quisiera ser... criar a mis hijos lo que es, dándole } \\
\text { todo lo mejor pero si no he estudiado, no conozco más si no el } \\
\text { fútbol, entonces qué hago, qué soluciones ahí busco, no tengo } \\
\text { estudio, no sé nada, mejor dicho, ni tengo nadie que me apoye, si } \\
\text { no lo único que tengo es ahí el reguero de chinitos. }\end{array}$ \\
\hline & Información & $\begin{array}{l}\text { Por lo menos yo cuando salga de acá, yo no sé que me toque in- } \\
\text { ventarme, pero yo no voy a volver a robar, es que ya la próxima } \\
\text { vez que yo me ponga a robar ya no me vuelven a traer acá, sino ya } \\
\text { es para el Buen Pastor y eso. }\end{array}$ \\
\hline & Anclaje & $\begin{array}{l}\text { Y lo del consumo es porque ya... desde los once años he consumi- } \\
\text { do mucho, O sea, yo en la calle consumía mucho, hasta en mi casa } \\
\text { lo hacía y eso, y o sea eso es lo que a mí me da miedo, o sea, salir } \\
\text { y que no más en la esquina ipun!, la ansiedad, O sea uno realmen- } \\
\text { te se prueba es a fuera, si puede o no, porque de verdad afuera va } \\
\text { a estar el problema de la familia, de la familia, el de si tiene hijos } \\
\text { afuera o no, el de consumo, el de su vida. Son muchas cosas que } \\
\text { se unen y uno por más que lo levanten a uno... }\end{array}$ \\
\hline & Núcleo figurativo & $\begin{array}{l}\text { Pues yo lo he trabajado, lo he trabajado mucho, lo he afrontado, } \\
\text { pero ahorita me di cuenta que no, el cambio del hogar es..., que- } \\
\text { dé con la misma influencia, O sea volví a recaer en las cosas que } \\
\text { supuestamente ya había trabajado y o sea no, y si eso fue aquí, } \\
\text { aquí que al menos no tiene influencia de nadie, porque a pesar de } \\
\text { todo, aquí no se hacen cosas así, o sea deshonestas grandes, o sea } \\
\text { no se hacen, pero afuera en la calle, es que no sé, no sé, nadie lo } \\
\text { obliga a uno a hacer las cosas, pero se trata de pronto de infiuen- } \\
\text { ciabilidad, o pues yo lo tomo así de que ahí venga vamos, y uno } \\
\text { ¡bueno, está bien, vamos!, sino que es de pensamiento, digamos } \\
\text { a mí yo soy una persona influenciable, pero en el pensamiento no, } \\
\text { yo no me quiero ir a trabar pero yo le apuesto que si salgo, sí. o } \\
\text { sea, me dejo influenciar mi pensamiento, más al otro día yo vuel- } \\
\text { vo, sin que esa persona vuelva y me lo repita. }\end{array}$ \\
\hline & & Dimensión personal: Motivaciones \\
\hline & Anclaje & $\begin{array}{l}\text { Yo creo que el estar aquí... Yo ya he estado dos veces acá y ya } \\
\text { como que le pega duro, ya no puedo seguir. Yo no sé que le depare } \\
\text { la vida a uno, pero yo pienso ahora, ino! eso no va pa nada, eso no } \\
\text { le da sino perdidas a uno, pues no pérdidas acá, pero si pérdidas, } \\
\text { por ejemplo el tiempo con los hijos de uno, por ejemplo yo en } \\
\text { ocho meses, imagínese yo en ocho meses, mis hijos cuando yo ya } \\
\text { salga y me vuelvan a ver... }\end{array}$ \\
\hline
\end{tabular}




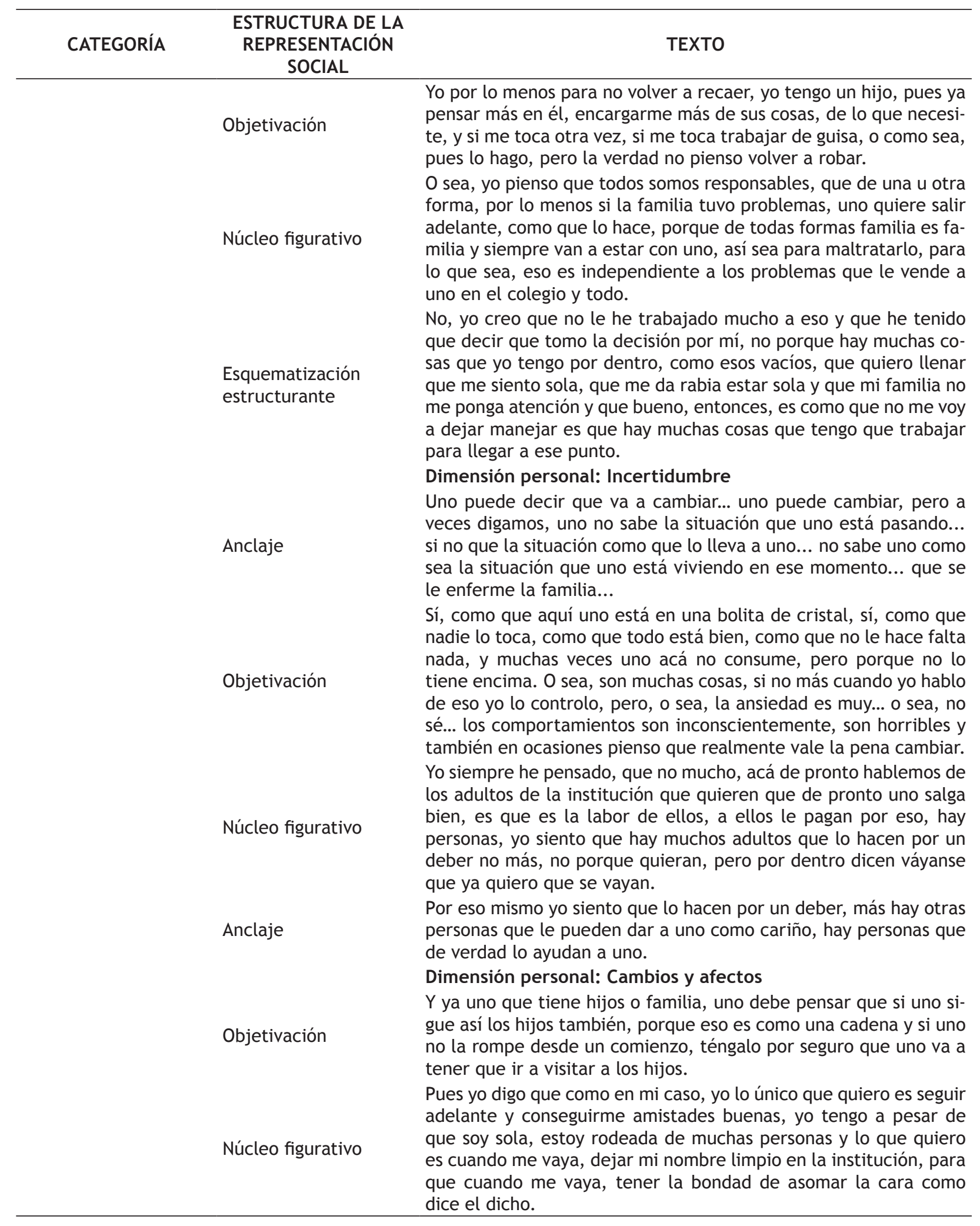




\section{ESTRUCTURA DE LA REPRESENTACIÓN SOCIAL}

Anclaje

Objetivación

Anclaje

Objetivación

Núcleo figurativo

Esquematización estructurante

Objetivación

Anclaje

\section{TEXTO}

Pues mi caso es diferente, pues porque en mi casa no se establecen normas y pues acá uno aprende normas que uno le sirve y son buenas. Pero en mi caso yo no pienso salir a cambiar a mi familia. Pienso cambiar de hogar y que me sigan ellos a mí.

Lo que ellos hacen con uno, porque de verdad son como cosas que tal vez ellos tengan la razón, que uno pueda cambiar y pueda hacer algo... por cada niña, que pueda cambiar su vida, que pueda modificar cosas, como un pago. Pues igual si yo necesito, el trabajo para mí es más gratificante, las personas que llevan seguimiento están bien. Pero yo digo que eso sí implica parte de uno, como querer cambiar, porque al igual uno se encontrará a muchas personas que quieren ayudarlo, pero si uno se empeña en seguir en lo mismo ¡imagínese!

Dimensión institucional: Oportunidad

Para mí es muy difícil recibir autoridad de personas desconocidas, como órdenes, porque siempre hice lo que quise, pero al final uno termina por entender que esto es para nuestro bien y bienestar, para reformarnos y aprender a ser personas responsables fuera de aquí y no volver a incurrir.

Yo pienso que es una forma de afrontar también nuestra situación de cuando estamos fuera de aquí del instituto y no volver otra vez. Porque ya un año aquí y no me he querido ir porque yo he tenido una oportunidad muy grande, yo tuve una oportunidad que me iba y yo no me quise ir, yo no me quiero ir, porque, no sé, primero porque estoy bien, segundo porque de pronto me han trabajado mis temores para hacer una realidad y porque pues yo tengo muchas ventajas, pero también no se sabe ni qué vaya a pasar conmigo más adelante.

Pero es que para eso existen, como hay personas que como que lo asechan, bueno no sé bien pronunciar bien la palabra... que como que le brindan una guía a uno, y le brindan alternativas claras y hay personas que ya tienen hasta los cuadernos y estudian y trabajan. O sea, hay como unas personas que de verdad lo quieren apoyar a uno; depende si uno va y busca las alternativas y comenta los casos por los cuales uno está, porque si uno se queda callado, yo no sé hacer esto, me voy a robar que es lo único que sé hacer y se echa a las pérdidas.

Yo como lo he dicho, el problema no está en salir, sino en saber aprovechar la salida, porque de qué le sirve a uno salir sin tener alternativas o ideas claras para salir.

O sea, por lo menos yo pienso que me parece muy bueno esto, que por lo menos acá por un momento uno como que hace un pare, sí como yo qué estaba haciendo, o qué hice malo, o qué me faltó: o por qué yo llegué acá. O sea, no solamente el delito, sino detrás de ese delito ¡cuántos problemas no tendrá la familia! pues muchas cosas, pues me parece muy bueno porque acá lo ayudan, más que hacerle acá envidia, o obligarlos, es como darle la opción de mirar que va a hacer de su vida, si sigue igual o qué puede cambiar, si sigue por un buen camino. 


\begin{tabular}{|c|c|c|}
\hline \multirow[t]{9}{*}{ CATEGORÍA } & $\begin{array}{l}\text { ESTRUCTURA DE LA } \\
\text { REPRESENTACIÓN } \\
\text { SOCIAL }\end{array}$ & TEXTO \\
\hline & & Dimensión institucional: Incredulidad \\
\hline & Núcleo figurativo & $\begin{array}{l}\text { Es que el consumo, a veces me veo una persona consumidora, } \\
\text { pero estable, ubicada, pero consumidora, pero no sé cómo es eso. } \\
\text { Otras veces me veo con los amigos que a veces mi familia me de- } \\
\text { cía, que es el salir a trabajar cambiar de ciudad, todas esa cosas, } \\
\text { sí. O sea, hay dos cosas que sé que debo coger dos caminos, O } \\
\text { sea, el día que yo salga, yo se que ahí es cuando realmente voy a } \\
\text { descubrir cuál es el bueno. Pero estoy entre los dos. }\end{array}$ \\
\hline & Anclaje & $\begin{array}{l}\text { Yo pienso que no me parece porque allá nadie se preocupa qué } \\
\text { problemas tenía está niña, por qué lo hizo, allá simplemente mé- } \\
\text { talo y pague independiente si coge más vicio o se daña, pero no se } \\
\text { da cuenta que uno como que todavía está como niño, sí, porque } \\
\text { uno puede tener } 17 \text { años, pero uno sigue viviendo cosas, y uno } \\
\text { merece la oportunidad de ser escuchado. Esos sitios, sí, siempre } \\
\text { y cuando uno esté acá por convencimiento, porque es para uno. } \\
\text { Pues si uno igual llega a una cosa de estas y no le ve el sentido, } \\
\text { uno para que está acá, o sea, darle la oportunidad a otra persona } \\
\text { que de verdad este mal que pueda cambiar, modificar. }\end{array}$ \\
\hline & & Dimensión social: Oportunidades laborales \\
\hline & Información & $\begin{array}{l}\text { Necesitaríamos otras cosas, como trabajo y no robar y no hacer lo } \\
\text { que los demás digan. }\end{array}$ \\
\hline & Objetivación & $\begin{array}{l}\text { Pero es que uno a veces va a pedir, y uno va y pide y le dicen jvaya } \\
\text { trabaje! ¡vaya y haga esto! ¡vaya a un lado y a otro!, a uno le da } \\
\text { piedra y mejor dicho yo me ponía a pelear.. que vaya y trabaje y } \\
\text { uno que hace si a uno no le dan trabajo... a veces a mi me decían } \\
\text { vaya y trabaje, entonces yo les decía, pues si me va a dar trabajo } \\
\text { yo me pongo a trabajar, pero un trabajo para usted como le voy } \\
\text { a dar. Entonces a uno le da mal genio, y del mal genio que le da, } \\
\text { lo lleva a uno a que robe y también a uno no le gusta estársele } \\
\text { humillando a nadie. }\end{array}$ \\
\hline & & Dimensión social: Apoyo de instituciones \\
\hline & Información & $\begin{array}{l}\text { Yo pienso que no, porque para eso existen partes como iglesias, } \\
\text { donde lo ayudan a uno, que la comunidad del barrio, las juntas } \\
\text { comunales, pues algunas porque no todas son... }\end{array}$ \\
\hline
\end{tabular}

\section{Discusión}

Es de recordar que la definición de representaciones sociales se refiere a la posición valorativa que las jóvenes tienen acerca de la delincuencia, como manifestación simbólica de algo real, que es parte de su cotidianidad y que es una forma de conocimiento social. Es una actividad mental, de pensamiento práctico, realizada por los grupos y por sus individuos.

Por ello, es importante preguntarse ¿qué es lo que piensan y sienten las menores con respecto a ellas mismas, a su condición jurídica, y como personas, a la no satisfacción de sus necesidades y a las responsabilidades que tienen los adultos con ellas? Es decir, preguntarse ¿Cuáles son sus representaciones? Muchos de los autores, tanto sociólogos como psicólogos, políticos y otros profesionales de las ciencias de la salud y ciencias sociales han dicho qué pasa con el adolescente, qué piensan, sienten y viven de acuerdo con el periodo de la vida en que están, pocas veces se les ha preguntado a ellos y menos en situaciones especiales los problemas que han generado una reacción en las otras personas.

En este trabajo se pudo ver que las menores son conscientes de su situación y la reconocen, aceptan en su mayoría la responsabilidad de sus actos, 
pero a su vez responsabilizan a los adultos de sus condiciones, sienten que estos han fallado en lo que estaban comprometidos hacer con ellas, y que su cuidado y protección se los han delegado a otras instituciones diferentes a la familia.

Aceptan que están involucradas en el mundo de la delincuencia, pero también la justifican, se apropian de ella como un medio de subsistencia, un estilo de vida al que observan como propio, que les facilita la vida, que les sirve no sólo para satisfacer necesidades mínimas, ni siquiera básicas, sino también otras necesidades creadas, externas y nocivas para ellas. Así objetivizan la delincuencia, la transforman en un símbolo en el que se concentra la existencia de una actividad, que es parte de su vida. Es un pensamiento práctico en la medida que les permite justificar sus actos delictivos y la materializan en la instrumentalización que hacen de ella.

Además, la información brindada por las menores muestra que esas experiencias cargadas de maltratos, abandonos, negaciones casi constantes de su infancia, han moldeado su razón de ser en el mundo, sus representaciones acerca de la vida y de su papel en ella. Dicho moldeamiento además se objetiviza cuando se hacen los razonamientos acerca de la delincuencia como estilo de vida, como un medio para su subsistencia y, a su vez, como víctima de un proceso de socialización en el que tuvieron pocas oportunidades de ser respetadas como niñas y como personas, o las que tuvieron se orientaron a no desarrollarse moralmente, a no aceptar al otro como ser humano, situaciones que por otra parte se convirtieron en estrategias cognitivas que le permitieron su subsistencia.

De acuerdo con las respuestas de las jóvenes, la delincuencia produce dolor y es valorada por ellas como algo negativo, que puede causar daño a otros. Sin embargo, esta estructura de representación social de las participantes no es lo suficientemente fuerte como para funcionar como inhibidora de su propia conducta delictiva.

La representación de la delincuencia en relación con su efecto en otras personas, fue vista por las adolescentes como perjudicial en la medida que reconocen que hacen daño, pero no pueden evitarlo. Entre sus explicaciones mencionan que "son ellas o son los otros". Esto se relaciona con la idea "no estar en el mismo bando" manifestación coherente con su etapa de desarrollo y que se vincula con la rebeldía; sin embargo, es una situación de riesgo, pues es probable que no se supere el permanecer en un bando, el de los desviados, que sea algo permanente, que troquele su vida, su existencia y su identidad.

La adolescencia es una etapa particular en la que se construye, se revalúa y se reconstruye permanentemente la identidad y la conciencia de sí mismo. Y es la información que se obtiene y se asimila en el medio, la que le permite dicho desarrollo humano. La dificultad surge cuando las condiciones de desarrollo no son óptimas y ni siquiera se cumple con los mínimos satisfactores, esta identidad se desdibuja o se calcan experiencias no tan positivas para la constitución de dicho adolescente.

Un factor importante de resaltar en las menores es el que se encuentra en las manifestaciones relacionadas con la atribución de la responsabilidad, en relación con su historia personal que ha estado cargada de odios, resentimientos, también de experiencias denigrantes, de abandonos y de abusos. Cuando se piensa que son niños los que los padecen, se puede pensar que se están matando las esperanzas, el futuro de jóvenes y existencia de toda una generación.

La delincuencia y aún más la violencia se convierte en un medio para encontrar la tranquilidad, la compensación a esos sufrimientos impartidos, en la mayoría de casos, por los adultos. Y son estos saberes preexistentes los que centran su propia existencia, es decir, lo que define su condición, su representación como tal, la que se traduce en acciones, pero que se ancla y, por tanto, las define y las hace parte de un grupo social.

Aunada a lo anterior se encuentra la necesidad de ser aceptada, y no por todas las personas, sino principalmente por sus iguales. El reconocimiento como persona, como sujeto que se construye con 
el otro, que sea aceptado, que cumple con las expectativas de un grupo social, le permite establecer vínculos que le dan soporte para continuar en esa construcción de la identidad; son vínculos nuevos, que se vuelven referentes de su vida y que se distancian de las primeras figuras de apego, cuando éstas existieron.

Además, este proceso propio de la adolescencia, es decir, la necesidad de establecer nuevos vínculos y apegos, se convierte en más significativo cuando hay vacíos en su grupo original. La adolescencia es una edad de búsqueda de pareja y de compañero sentimental, que precisa una necesidad propia de los adolescentes en lo sexual y afectivo, necesidad decisiva para su futuro cuando se hace una inadecuada elección. Tanto los iguales, como la pareja, se convierten en factores decisivos para que se aparten, se unan o continúen en la vida delincuencial.

La familia, representada principalmente en la figura de los padres, la consideran como un elemento decisivo para su vida. Reconocen que la autoridad, el estilo educativo, la comunicación y el amor y cuidado son positivos o negativos, de acuerdo como se manifiesten, y que influye en lo que ellas son hoy. Sin embargo, aún reconociendo que la familia no fue la más adecuada para su crecimiento y construcción personal, en el futuro la consideran un fuerte elemento de red de apoyo que las va a sacar, que las va a alejar y que va a contribuir a cambiar su mundo, su estilo de vida y su futuro; centran algunas esperanzas en ella como una alternativa de supervivencia en lo lícito, que les permita pasar a ser adultas sanas y responsables. Consideran que la familia puede ayudar a normalizar algo que ha estado desviado.

En cuanto al futuro, éste es tan incierto como lo ha sido parte de su vida, y como lo es la adolescencia. Es una percepción de futuro, en la mayoría de casos, cargado de esperanzas, pero a su vez de temores, incertidumbre, con respecto a sucumbir nuevamente a lo que consideran las llevó a delinquir, llámese familia, amigos o pareja.

Saben que al estar en la institución es una oportunidad, pero no se pueden apartar de percibir a la autoridad (policía y reeducadores) como amenazante. Así, la institución no es deseada para su futuro, no quieren regresar a ésta ni a otra similar, consideran que la institución no está diseñada para ellas, ni acorde con sus necesidades, sino para los adultos que la crearon. Las jóvenes poseen sueños, pero pocas alternativas, y esperan encontrar instituciones sociales (diferentes a las de reeducación y resocialización) o personas que les ofrezcan oportunidades positivas de sobrevivencia.

Los análisis de las respuestas y cuestionamientos alrededor del foco de representación de la delincuencia llevan a apostarle a un trabajo que sea significativo en su vida, que realmente sea un trabajo educativo, que fortalezca su inteligencia emocional, su conciencia moral y les permita ser más fuertes para afrontar las dificultades que se le presenten. El apoyo institucional tendría la responsabilidad de ejecutar programas más centrados en el desarrollo de lo humano, brindando adicionalmente una educación de buena calidad; sustituir en un momento dado las figuras con las que debieron haber establecido vínculos y no lo pudieron hacer. De acuerdo con las respuestas de las menores, la institución les ha permitido establecer vínculos importantes con los profesionales que laboran allí, pues de ellos reciben cuidados, protección y afecto. Adicionalmente, dentro de este proceso de educación debe apuntársele al desarrollo del autocontrol y al fortalecimiento de la empatía que se relacione con disciplina exigida desde lo académico y laboral.

En cuanto a la prevención, la comunidad debe apropiarse de que en general todos somos parte del problema y por tanto parte de la solución. La comunidad debe participar activamente en dos niveles: en la generación de programas en los que participen las familias, el sector educativo (colegios y escuelas) y grupo de pares en la primera fase, en la que se pueden empezar a manifestar conductas predelincuenciales.

Ya en comportamientos delictivos consolidados, los jóvenes sí deben permanecer institucionalizados, con programas, como se dijo, centrados en el desarrollo humano, pero adicionalmente trabajando en la comunidad, produciendo cambios 
que normalicen la situación y preparen al joven para su salida. Que sus representaciones sean tenidas en cuenta y las acciones propuestas puedan entrar a competir con las existentes, pues debe haber primero un cambio de la información, de actitudes acerca de la delincuencia y una modificación de los significados de la misma. Las acciones para lograr esto implican la participación de instituciones tradicionales y de otras creadas para estos propósitos.

En general, los programas que se desarrollen tanto directamente con el joven, como integradamente con su familia y su contexto educativo y social inmediatos, deben ser programas basados en el desarrollo humano, que le permitan al joven empoderarse en su contexto y potencializar lo que ha sido desarrollado en las instituciones, con el apoyo de los adultos y de otras personas y profesionales que crean que todavía los menores tienen futuro.

\section{Referencias}

Alzate, M. V., Arbeláez, M. C. \& Arango, S. (2000). Representaciones de niños y niñas sobre el maltrato institucional. Revista Ciencias Humanas, 18. ICBF.

Clemente, M. \& Espinosa, P. (2001). La mente criminal. Teorías explicativas del delito desde la Psicología Jurídica. Madrid: Dykinson.

Cortés, C.E. (2002). Teoría de las representaciones sociales. Extraído el 3 de mayo de 2010 en http://cristianenrique.tripod/trabajosocialydiscapaidadvisual

FES. (1998). Reincidencia juvenil y libertad asistida en Santa Fe de Bogotá. Impresos Financieros.

Garrido, V. (1984). Delincuencia y Sociedad. Madrid: Temis.

Garrido, V., Stangeland, P. \& Redondeo, S. (1999). Principios de criminología. Valencia: Tiran lo Blanch.
Garrido, V. \& Vidal, M. (1989). Lecturas de pedagogía correccional. Valencia, España: Nau Libres.

Gibbons, D. (1980). Delincuentes juveniles y criminales. México: Fondo de Cultura Económica.

Glueck, S. \& Glueck, E. (1950). Unraveling Juvenile Delinquency. Cambridge: Harvard University Press.

Gutiérrez, J.D. (1998). La teoría de las representaciones sociales y sus implicaciones metodológicas en el ámbito psicosocial. Psiquiatría pública, 10 (4), 211-219.

Hoffman, L., Paris, S., \& Hall, E. (1996). Psicología del desarrollo hoy. Madrid: Mc Graw Hill.

Ibáñez, T. (2001). Psicología social constructivista. México: Universidad de Guadalajara.

Ibáñez, T. (1988). El conocimiento de la realidad social. Barcelona: Senday.

López-Rey Arrojo, M. (1981) Criminología. Teoría, delincuencia juvenil, predicción y tratamiento. Madrid: Aguilar.

Molina, C. M. (1994). Fundamentos de criminología. Bogotá: Temis.

Molina, P. (1996). Criminología, una introducción a sus fundamentos teóricos para juristas. Valencia, España: Tirant Lo Blanch.

Mora, M. (2002). La teoría de las representaciones sociales de Serge Moscovici. Atenea Digital, 2. Universidad de Guadalajara (México). Extraído el 3 de mayo de 2010 en http:// blues.uab.es/athenea/num2/Mora.pdf

Moscovici, S. (1974). La era de las multitudes: un tratado histórico de psicología de las masas. México: Fondo de Cultura Económica.

Moscovici, S. (1987). Psicología social. Barcelona: Paidós. 
Ruiz, M. (1998). Menores Infractores. Pedagogía especializada. Extraído el 3 de mayo de 2010 en biblioteca.universia.net/ficha. do?id $=37927208$

Stoff, D., Breiling, J. \& Maser, J. (2002). Conducta antisocial: causas, evaluación y tratamiento. Vol. 1. México: Oxford.
Torrente, G. \& Merlos, F. (1999). Aproximación a las características psicosociales de la delincuencia de menores en Murcia. Anuario de Psicología Jurídica, pp. 39-63. Murcia, España.

Vega, A. (1994). Psicología de los inadaptados sociales. Madrid: Narcea. 
